RENATA WELINSKI DA SILVA SEABRA

A regulamentação internacional ambiental e a responsabilidade corporativa

Dissertação de Mestrado

Orientadora: Professor(a) Dr.(a) Elizabeth de Almeida Meirelles

UNIVERSIDADE DE SÃO PAULO

FACULDADE DE DIREITO

SÃO PAULO

2020 
RENATA WELINSKI DA SILVA SEABRA

\section{A regulamentação internacional ambiental e a responsabilidade corporativa}

Dissertação apresentada à Banca Examinadora do Programa de PósGraduação em Direito, da Faculdade de Direito da Universidade de São Paulo, como exigência parcial para obtenção do título de Mestre em Direito, na área de concentração Direito Internacional do Meio Ambiente, sob a orientação da Professora Dra. Elizabeth de Almeida Meirelles.

UNIVERSIDADE DE SÃO PAULO

FACULDADE DE DIREITO

SÃO PAULO

2020 
Seabra, Renata Welinski da Silva

A regulamentação international ambiental e a responsabilidade corporativa; Renata Welinski da

Silva Seabra; orientadora Elizabeth de Almeida

Meirelles -- São Paulo, 2020.

$150 \mathrm{f}$.

Dissertação (Mestrado - Programa de Pós-Graduação em Direito Internacional) - Faculdade de Direito, Universidade de São Paulo, 2020.

1. Direito Internacional do Meio Ambiente. 2. Responsabilidade corporativa. 3. Responsabilidade extraterritorial. 4. Dano ambiental transnacional. 5. Empresas multinacionais. I. Meirelles, Elizabeth de Almeida, orient. II. Título. 
Nome: SEABRA, Renata Welinski da Silva

Título: A regulamentação internacional ambiental e a responsabilidade corporativa

Dissertação apresentada à Banca Examinadora do Programa de PósGraduação em Direito, da Faculdade de Direito da Universidade de São Paulo, como exigência parcial para obtenção do título de Mestre em Direito, na área de concentração Direito Internacional do Meio Ambiente.

\section{Aprovado em:}

\section{Banca Examinadora}

Prof. Dr.:

Instituição:

Julgamento:

Prof. Dr.:

Instituição:

Julgamento:

Prof. Dr.:

Instituição:

Julgamento: 


\section{AGRADECIMENTOS}

A realização deste trabalho somente foi possível mediante a perseverança necessária para a superação dos meus limites e pelo amor ao conhecimento, auxiliada pela descoberta do catolicismo durante minha jornada.

Todo desafio encerra a vontade de realizar algo por um propósito determinado; para o qual precisamos contar com apoios durante a caminhada.

Assim, externo os meus agradecimentos ao meu esposo Ricardo, sem o qual não poderia ter-me dedicado a estes estudos e à minha filha, Maria Carolina, pela paciência em ter uma mãe ausente durante o período de sua redação. Ambos, me fazem querer ser uma pessoa melhor.

Aos meus pais, que me ensinaram o valor da honestidade, do caráter, do conhecimento e da perseverança.

À querida Professora Doutora Elizabeth de Almeida Meirelles, pela confiança a mim depositada ao orientar a presente dissertação, o que propiciou a expansão de meu horizonte de conhecimento; bem como pela necessária tolerância e paciência para que este resultado fosse alcançado.

Às minhas colegas de mestrado (e, no momento, já mestres): Naíma Perrella Milani e Paula Monteiro Danese, pela amizade e apoio constante, repleto de palavras de encorajamento em momentos desafiadores. 
Water, water, every where, And all the boards did shrink;

Water, water, every where, Nor any drop to drink.

(The Rime of the Ancient Mariner, por Samuel Taylor Coleridge, 1798). 


\section{RESUMO}

SEABRA, Renata Welinski da Silva. A regulamentação internacional ambiental e a responsabilidade corporativa. 2020. 153 f. Dissertação (Mestrado) - Faculdade de Direito, Universidade de São Paulo, São Paulo, 2020.

A regulamentação internacional da proteção ambiental e a responsabilidade corporativa englobam o ambiente regulatório existente para assegurar a proteção ambiental em caso de transferência de instalações industriais relacionadas às atividades perigosas realizadas por empresas multinacionais, considerando-se os limites de tolerância dos recursos naturais. Neste contexto, são estudadas questões de regulamentação envolvendo a responsabilidade dos Estados, os quais, pelo princípio do dever de proteção (“due diligence”), devem assegurar que tais empresas, com sede estatutária localizadas em seus territórios, não causem danos ambientais extraterritoriais. Discorre-se sobre a possibilidade dos órgãos judiciais locais por meio da interpretação da doutrina forum non conveniens, apreciarem um litígio envolvendo danos ambientais de efeitos transnacionais, cujos impactos se fazem sentir no Estado de localização de sua subsidiária. Assim, será analisada a aplicação da Lei de Atos Ilícitos no Exterior norte-americana e casos julgados no sistema jurídico da Common Law, avaliando-se os limites da jurisdição do Direito Internacional Privado. São estudadas iniciativas corporativas e da ONU que visam melhorar o desempenho ambiental das empresas multinacionais pela adoção de normas voluntariamente baseadas em instrumentos jurídicos vinculantes. A busca dos Estados sede das empresas multinacionais por padrões internacionais de RSC, as recentes iniciativas estatais de regulamentação da proteção ambiental extraterritorial, bem como os efeitos para o Direito Internacional das teorias sobre a responsabilização de tais empresas também são estudados. Por fim, é discutido o eventual surgimento de obrigações diretas para empresas multinacionais pela adoção do princípio do dever de proteção em suas operações extraterritoriais e suas implicações para os Estados de localização das empresas subsidiárias.

Palavras-chave: 1. Direito Internacional do Meio Ambiente. 2. Responsabilidade corporativa. 3. Responsabilidade extraterritorial. 4. Empresas multinacionais. 5. Dano ambiental transnacional 


\begin{abstract}
SEABRA, Renata Welinski da Silva. International environmental regulation and corporate responsibility. A regulamentação internacional ambiental e a responsabilidade corporativa. 2020. 153 f. Dissertação (Mestrado) - Faculdade de Direito, Universidade de São Paulo, São Paulo, 2020.
\end{abstract}

International environmental protection regulations and corporate responsibility encompass the existing regulatory environment to ensure environmental protection in the event of transfer of industrial facilities related to hazardous activities carried out by multinational companies, taking into account the limits of tolerance of natural resources. In this context, regulatory issues involving the responsibility of States are studied, which, under the due diligence principle, should ensure that such companies, with their statutory seat located in their territories, do not cause extraterritorial environmental damage. It is discussed about the possibility of local courts, through the interpretation of the forum non conveniens doctrine, to consider a dispute involving environmental damage of transnational effects, whose impacts are felt in the state of location of its subsidiary. Thus, the application of the Law on Alien Tort Claims Act and cases sued in the Common Law legal system will be analyzed, and the limits of the jurisdiction of Private International Law will be evaluated. Corporate and UN initiatives aimed at improving the environmental performance of multinational companies by adopting standards voluntarily based on binding legal instruments are evaluated. The study also analyses the search by home states of multinational corporations for international standards of corporate social responsibility, recent state initiatives to regulate extraterritorial environmental protection and the effects on international law of the theories of corporate accountability. Finally, the possible emergence of direct obligations to multinational companies by adopting the due diligence principle in their extraterritorial operations and its implications for the states of location of subsidiary companies is discussed.

Keywords:1. International Environment Law. 2. Corporate responsibility. 3. Extraterritorial responsibility. 4. Transnationals corporations. 5. Transnational environmental harm. 


\section{LISTA DE ABREVIATURA E SIGLAS}

\begin{tabular}{|c|c|}
\hline $\mathrm{CDH}$ & Conselho de Direitos Humanos \\
\hline CDI & Comissão de Direito Internacional \\
\hline $\mathrm{CEDH}$ & Corte Europeia de Direitos Humanos \\
\hline CEPAL & Comissão Econômica para a América Latina e Caribe \\
\hline CIJ & Corte Internacional de Justiça \\
\hline GRI & Global Report Initiative \\
\hline GTETDH & $\begin{array}{l}\text { Grupo de Trabalho Intergovernamental das Nações Unidas } \\
\text { sobre Empresas Transnacionais e Outros Empreendimentos } \\
\text { em relação a Direitos Humanos }\end{array}$ \\
\hline ICC & International Chamber of Commerce \\
\hline MNC & Multinacional Company \\
\hline OCDE & $\begin{array}{l}\text { Organização para a Cooperação e Desenvolvimento } \\
\text { Econômico }\end{array}$ \\
\hline OECD & Organization for Economic Cooperation and Development \\
\hline OIT & Organização Internacional do Trabalho \\
\hline $\mathrm{ONU}$ & Organização das Nações Unidas \\
\hline PIDCP & Pacto Internacional dos Direitos Civis e Políticos \\
\hline RSC & responsabilidade social corporativa \\
\hline TNC & Transnational Companies \\
\hline UN & United Nations \\
\hline UNCTAD & United Nations Centre for Trade and Development \\
\hline
\end{tabular}




\section{LISTA DE TABELAS}

Tabela 1 - Casos apresentados ao Conselho de Direitos Humanos da ONU e aos Sistemas regionais de Direitos Humanos. .47

Tabela 2 - Setores específicos identificados com as atividades dos defensores ambientais assassinados em 2016 e em 2018 ......................................62

Tabela 3 - Requisitos de RSC adotados por Estados.............................................75 


\section{SUMÁRIO}

1 INTRODUÇÃO.........................................................................................13

1.1 Justificativa da escolha do tema e sua importância..........................................15

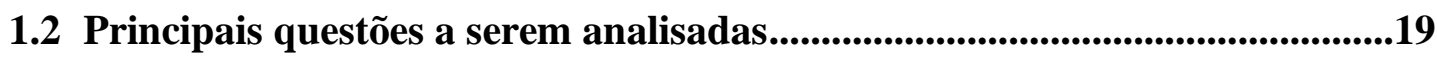

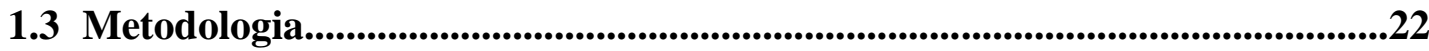

\section{A RESPONSABIDADE DOS ESTADOS POR DANOS AMBIENTAIS NO}

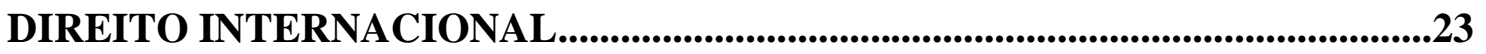

2.1 O dano transfronteiriço como um conceito que abrange o dano

transnacional.

2.1.1 Uma breve análise do Projeto de Artigos sobre a Responsabilidade dos Estados por Atos Internacionalmente Ilícitos da Comissão de Direito Internacional.

2.1.2 A responsabilidade do Estado da sede da empresa multinacional à luz do princípio do dever de proteção.

2.1.2.1 Os Projetos de Artigos da Comissão de Direito Internacional sobre Dano Transfronteiriço.

2.1.3 Os Princípios de Maastricht e a responsabilização extraterritorial dos Estados

2.1.4 A inclusão da proteção ambiental na regulamentação internacional de direitos humanos. 44

2.1.5 A inclusão do ecocídio no Estatuto de Roma do Tribunal Penal Internacional. .48

2.2 O Direito Internacional do Meio Ambiente, as empresas

multinacionais e a responsabilidade social corporativa .50

2.2.1 A ONU e as empresas multinacionais 56

2.2.1.1 Projeto de Código de Conduta para corporações Transnacionais. .57

2.2.1.2 Projeto de instrumento jurídico para regulamentar, no Direito Internacional dos Direitos Humanos, as atividades de empresas 
transnacionais e outros empreendimentos de negócios.

2.2.2 A obrigatoriedade das normas de responsabilidade social corporativa.

2.2.3 A regulamentação internacional de responsabilidade social

corporativa e a proteção ambiental............................................................ 73

2.2.4 Princípios legais emergentes e a responsabilidade social corporativa. .77

2.3 O Direito Internacional do Meio Ambiente e os desafios para a sua implementação. .82

2.3.1 Os limites da jurisdição no direito internacional público..........................83

2.3.2 Os limites da jurisdição no direito internacional privado.........................8 89

2.3.3 A regulamentação extraterritorial de responsabilidade social corporativa para empresas multinacionais. .92

3 A BUSCA DE PADRÕES DE RESPONSABILIDADE SOCIAL CORPORATIVA DAS EMPRESASMULTINACIONAIS....................................98

3.1 As novas práticas de responsabilidade social corporativa

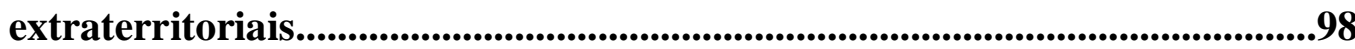

3.1.1 Ações privadas por danos ambientais.................................................... 109

3.1.1.1 Ações baseadas em atos ilícitos...........................................................113

3.1.1.2 A lei norte-americana de Atos Ilícitos no Exterior.................................115

3.1.2 Teorias sobre a responsabilização da empresa sede das

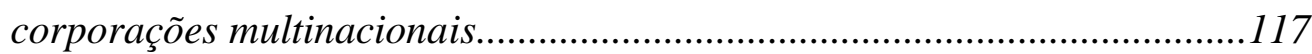

3.1.3 Implicações para o direito internacional...............................................119

\section{A REGULAMENTAÇÃO INTERNACIONAL DAS EMPRESAS}

MULTINACIONAIS

4.1 A caminho de um direito internacional de responsabilidade social corporativa? 


\section{INTRODUÇÃO}

A transferência de atividades industriais perigosas 1 descreve a tendência de investimento de empresas multinacionais2, geralmente sediadas em países desenvolvidos no estrangeiro, em países em desenvolvimento, motivadas por padrões ambientais menos restritivos ou inexistentes, expondo franco confronto entre os ganhos socioeconômicos e o risco de dano transnacional3.

Segundo Soares, a parte mais importante no que se refere ao combate à poluição, refere-se à regulamentação internacional da produção, comércio e transporte de determinados produtos (sobretudo químicos) de uso corrente nas atividades industriais dos Estados e desde sempre submetidos, bem como da administração racional dos resíduos perigosos ao meio ambiente, $\mathrm{n}$ oque se refere às medidas para sua redução, depósitos seguros e para o seu movimento transfronteiriço (SOARES, 2001).

Analisando-se em escala global e em contraste com os padrões regulatórios aplicados nos Estados Unidos da América, Alemanha e Holanda com aqueles aplicados ou deficientemente executados, na África Central, Leste Europeu ou partes da Ásia; o argumento de que as empresas podem ser persuadidas a deslocar suas indústrias e resíduos perigosos para regimes menos regulados e locais menos onerosos para fazer o seu "negócio sujo" torna-se persuasivo (CLAPP, 2001; PELLOW, 2007).

Tal fenômeno tem sido impulsionado pelos efeitos da globalização, como a redução dos custos de investimento causada pelo avanço na tecnologia e comunicação, além do amplo acesso à exploração de matérias primas e às condições de produção mais favoráveis encontradas em Estados com regulamentação ambiental menos restritiva, permitindo que empresas multinacionais exerçam suas atividades de acordo com padrões de

\footnotetext{
1 A transferência de atividades, os produtos e os serviços de uma empresa para outro lugar, região ou país, buscando benefícios comerciais, redução de gastos, maior rentabilidade e produtividade é também conhecida pelo termo deslocalização. Como exemplos de indústrias perigosas, as quais são conhecidas por apresentarem elevados níveis de toxicidade e/ou poluição, citam-se as oriundas de indústrias extrativas, pesadas, químicas, têxteis e eletrônicas.

2 Adota-se, por conveniência, a noção estilizada de empresas multinacionais, que engloba uma empresa sede, localizada em seu país de origem e vinculada com suas empresas afiliadas estrangeiras por meio de relações de controle (ZERK, 2011, p. 49-51).

$3 \mathrm{O}$ dano transnacional refere-se à atividade de uma empresa multinacional desenvolvida por uma subsidiária num país estrangeiro e aos respectivos impactos ambientais nesse país, enquanto o dano transfronteiriço caracteriza-se por referir-se à uma atividade industrial existente no território de um Estado, com repercussões ambientais para além das fronteiras desse Estado (BARROS, 2012, p. 21).
} 
qualidade ambiental diferenciados, estabelecendo-se em nível internacional, duplos padrões de controle da poluição.

A preocupação não se encerra apenas na exportação de resíduos, como também nos impactos dos investimentos diretos estrangeiros de empresas multinacionais em indústrias perigosas em países em desenvolvimento (CLAPP, 2001, p. 104-125).

Tal fenômeno tem sido descrito como o "imperialismo tóxico" ou "exportador de processos perigosos" (WALKER, 2012, p. 102) a "corrida para o topo" (de padrões ambientais), os "paraísos de poluição" e a "exportação de perigos" (STONE, 2012, p. 95). Sobre este aspecto, Low e Gleeson (1998, p. 120) argumentam que "o sistema político global, composto por países competidores, pode não ser apropriado para garantir a proteção ambiental", apontando para as formas nas quais a liberalização comercial e globalização econômica têm permitido maior discricionariedade na locação de atividades industriais e disposição de resíduos; e que acordos comerciais tem geralmente falhado em reconhecer as preocupações ambientais como uma fator de restrição (WALKER, 2012, p. 95).

Não obstante, não se trata apenas de responsabilizar apenas os países desenvolvidos: "Eventualmente, potências emergentes, inexoravelmente, no entanto, buscam no exterior, recursos naturais que precisam, com vastas consequências" (ECONOMY e MICHAEL, 2014, p. 2) , como por exemplo, tem-se que $80 \%$ dos investimentos diretos chineses na Austrália, considerando o período entre 2005 a meados de 2013, estão concentrados na indústria da mineração, dos quais 50\% foram em minério de ferro, totalizando cerca de 30 bilhões de dólares (ECONOMY e MICHAEL, 2014, p. 61).

Por conseguinte, coloca-se a questão da responsabilização por danos ambientais, sendo que uma das vias possíveis é a responsabilização internacional de atores privados, não obstante as empresas multinacionais não são reconhecidas como sujeitos tradicionais do Direito Internacional e, portanto, a possibilidade de lhes impor obrigações diretamente permanece controversa na doutrina. Entretanto, não há nada inerente ao Direito Internacional que impeça os Estados de estabelecerem obrigações diretamente para as empresas, bem como para grupos corporativos (ZERK, 2011, p. 76).

Em contrapartida, têm sido instauradas diversas iniciativas regulatórias voluntárias em fóruns internacionais, como no âmbito das Organizações das Nações Unidas (ONU) e da Organização para a Cooperação e Desenvolvimento Econômico (OCDE), com o intuito de desenvolver iniciativas de responsabilidade social corporativa (RSC).

Há que se considerar o papel das normas de RSC - de caráter voluntário - 
adotado por empresas multinacionais como forma de auto-regulamentação para garantir a devida proteção ambiental e a licença social4 para operar. No entanto, tais normas atingem um número limitado de empresas e um conjunto mínimo de direitos, além de não preverem critérios de monitoramento, muito menos a adoção de medidas e/ou sanções em caso de não cumprimento.

Desta forma, derroga-se ao Estado - principal pessoa jurídica internacional, o papel de regulador da conduta privada em termos de responsabilização e, portanto, detentor do dever de proteger o meio ambiente, apesar da dificuldade das autoridades competentes em aplicar eventuais normas jurídicas internacionais existentes.

O quadro supracitado permite considerar a necessidade do reconhecimento de obrigações independentes do Estado sede da empresa multinacional5, sendo necessária, todavia, a análise de suas obrigações internacionais extraterritoriais.

Baseada nestas premissas, a presente dissertação de mestrado analisará se a configuração atual da regulamentação internacional ambiental - de caráter juridicamente vinculante e voluntária - contribuem para o avanço da responsabilização das empresas multinacionais em casos de danos ambientais transnacionais.

\subsection{Justificativa da escolha do tema e sua importância}

Os recursos naturais do planeta Terra têm sido amplamente explorados pela humanidade e as consequências negativas para o meio ambiente causadas pelo seu uso

\footnotetext{
4 A licença social é uma permissão informal dada pelas partes interessadas aos empreendimentos para que operem, produzam e ampliem em determinada região e determinado contexto. Como a comunidade participa do processo de instalação de novas empresas em uma região, principalmente através do licenciamento ambiental, é fundamental que a mesma aprove os impactos ambientais e sociais decorrentes da instalação e operação dos novos empreendimentos (FUNDAÇÃO DOM CABRAL, 2013).

5 Define-se Estado sede da empresa multinacional como o local onde é principalmente exercido o controle sobre a atividade da multinacional, incluindo as suas subsidiárias, e onde são traçados os objetivos a alcançar e definidas as atividades a desenvolver. Outras definições incluem o local de incorporação da empresa e a nacionalidade dos proprietários ou daqueles que exercem controle sobre as suas atividades (BARROS, 2012, p. 19).
} 
industrial têm sido registrados até mesmo na literatura, como pelo escritor britânico Charles Dickens, em seu romance Tempos Difíceis, onde descreve os sinais da poluição na cidade de Coketown devido a atividade fabril como "[...] serpentes de fumaça que nunca se desenrolavam de todo. Havia um canal negro e um rio que corria púrpura por causa da tintura malcheirosa [...]"6.

Analogamente, a referência sobre poluição contida no livro Tempos difíceis, insere-se facilmente no conceito denominado Antropoceno7, o qual considera as atividades humanas como causadoras dos mais adversos impactos ao planeta e desestabilização do sistema da Terra, tais como: mudança climática, poluição química e atmosférica, degradação da água e do solo, sobrecarga de nutrientes e a massiva perda de espécies e seus habitats (ROCKSTRÖM; KLUM, 2015).

Diferentemente do ocorrido com as atividades de geração de energia nuclear, as quais foram amplamente regulamentadas pela Agência Internacional de Energia Atômica (AIEA) após o acidente de Chernobyl, ocorrido na cidade de Prypiat, Ucrânia, em 1986, as atividades industriais perigosas não são regulamentadas em nível internacional, o que dificulta o estabelecimento de um regime regulatório consistente, capaz de assegurar a devida proteção ambiental em nível global.

O caso do acidente ambiental ocorrido na subsidiária da empresa norteamericana Union Carbide, em Bopal, Índia, suscita questões sobre a responsabilização e a conduta das empresas multinacionais por sérios danos ambientais. Em 1989, foi homologado um acordo civil no valor de 470 milhões de dólares pela Dow Chemical, empresa que adquiriu a Union Carbide, no qual não se reconhece as doenças e defeitos de nascimento pós-acidente, nem faz quaisquer concessões para a contaminação8.

Relevante mencionar o pior acidente ambiental ocorrido no Brasil em novembro

6 DICKENS, 1976, p. 37.

7 O Antropoceno surgiu como um termo científico popular usado por cientistas, pelo público cientificamente engajado e pela mídia para designar o período da história da Terra durante o qual os seres humanos têm uma influência decisiva no estado, dinâmicas e futuro do sistema da Terra (WORKING GROUP ON THE “ANTHROPOCENE, 2019).

8 O vazamento de 40 toneladas de isocianato de metila utilizado na fabricação do pesticida Sevin, utilizado para pulverizar plantações na região de Bopal. na empresa Union Carbide ocorrido em 1984 em Bopal, Índia, acarretou a morte de 8-10.000 pessoas as primeiras 72 horas e de outras 15.000 devido à exposição ao gás. Outras 120.000 têm condições médicas crônicas que requerem constante cuidados médicos. Comparativamente, estima-se que Chernobil tenha causado 57 mortes diretas e mais 4.000 mortes por câncer). A descontaminação do local do acidente não foi realizada. O meio ambiente, nas redondezas da fábrica, está altamente contaminado e as toxinas alcançaram o lençol freático. Estima-se que 25.000 pessoas não têm uma fonte regular de água potável e são forçadas a beber esta água contaminada com químicos tóxicos. (PESTICIDE ACTION NETWORK UK, 2018). 
de 2015, envolvendo o rompimento de um dique com cerca de 40 milhões de m3 de rejeitos de mineração da empresa Samarco (THE GUARDIAN, 2018) - joint-venture entre as empresas australiana BHP Billiton e a brasileira Vale - tendo como consequência 19 mortos, a destruição de comunidades e de ecossistemas, cuja lama atingiu o oceano Atlântico. Ambas estão sendo responsabilizadas judicialmente localmente quanto às ações necessárias de compensação e remediação.

Para exemplificar a prática jurisprudencial internacional de responsabilizar a empresa sede devido à sua relação corporativa com a subsidiária, citam-se os casos Wiwa vs. Royal Dutch Petrolium, litigado nos Estados Unidos da América, e Lubbe vs. Cape litigado no Reino Unido, nos quais as primeiras foram responsabilizadas por violações de direitos humanos perpetradas pela segunda, ou seja, pelas respectivas empresas subsidiárias.

De acordo com Sands e Peel (2012), regras internacionais relacionadas às substâncias e atividades perigosas ainda não foram definidas ou aplicadas nos moldes de uma estratégia regulatória coordenada, sendo evidenciada a falta de uma definição geral do que constitui uma atividade ou substância perigosa.

Em detrimento à adoção de tratados, a comunidade internacional tem estabelecido diretrizes de políticas e declarações que evidenciam no âmbito do Direito Internacional, o caráter transfronteiriço do dano ambiental e a responsabilidade dos Estados, como nos Princípios 21 e 22 da Declaração de Estocolmo sobre Meio Ambiente Humano, de 1972.

Relevante mencionar o Princípio 14 da Declaração do Rio de Janeiro sobre Meio Ambiente e Desenvolvimento, de 1992, o qual reitera a necessária cooperação dos Estados para desestimular ou prevenir a realocação e transferência, para outros Estados, de atividades e substâncias que causem degradação ambiental grave ou que sejam prejudiciais à saúde humana; não podendo o Estado sede da empresa multinacional, ser indiferente em relação às atividades a serem desempenhadas por estas empresas em território estrangeiro.

No entanto, não estabelece a definição do termo degradação ambiental grave, fato o qual limita a ação dos Estados e possibilita o questionamento por partes interessadas.

Não há um tratado que verse sobre a conduta das empresas multinacionais e geralmente, sua responsabilização, em caso de danos transnacionais ocorre no âmbito do

9Ação coletiva impetrada contra a Shell nos Estados Unidos da América, na qual a empresa foi acusada em cortes americanas de cumplicidade na morte de ativistas nigerianos pela preservação do meio ambiente, entre eles o Nobel de Literatura Ken Saro-Wiwa, enforcado em 1995 (BBC, 2009). 
Estado de origem10 ou Estado de localização da empresa subsidiária e não em uma corte internacional especializada em matérias ambientais a qual responsabilize os Estados por danos extraterritoriais, tendo como consequência, a resolução de controvérsias nos contenciosos nos órgãos judiciais internacionais. Desconsidera-se, portanto, a responsabilização do Estado sede da empresa multinacional em casos de danos ambientais transnacionais.

$\mathrm{Na}$ ausência de regulamentações juridicamente vinculantes, a adoção de uma agenda regulatória voluntária pelos Estados e pelas empresas multinacionais tem-se apresentado como indutora de melhores práticas de conduta e de proteção ambiental.

No entanto, o grau de atendimento às estas normas voluntárias por Estados e pelas empresas multinacionais, bem como a adoção de padrões de operação envolvendo substâncias tóxicas equivalentes ou não menos restringentes que aquelas existentes em seu Estado sede da empresa multinacional aplicáveis aos seus processos produtivos, não estão claramente definidos, considerando que a proibição da utilização de duplos padrões não está definida em nenhuma norma internacional, cabendo ao Estado de localização da empresa subsidiária definir os seus padrões de proteção ambiental.

Atualmente, não há padrões de operação setoriais uniformizados internacionalmente envolvendo atividades perigosas e a sua cadeia de valor, os quais estabeleçam critérios de construção e operação, incluindo parâmetros de prevenção e controle de poluição ambiental, preparação as emergências, descomissionamento e de prevenção de danos transnacionais. Tais padrões apresentam-se relevantes à medida que tais atividades têm aspectos ambientais significativos relacionados ao seu ciclo de vida e contribuem de forma diferenciada nos níveis dos limites de planeta, sendo necessária, portanto, uma análise consistente do grau de impacto de cada atividade, considerando-se as particularidades de cada ecossistema.

Embora alguns Estados definam os critérios para a realização de estudos de avaliação e de impacto ambiental de atividades perigosas e/ou que causem impacto ambiental significativo previamente à instalação das unidades produtivas; tais exigências e definições não são harmonizadas em nível internacional, o que pode levar a distorções no que tange à efetiva proteção ambiental, facilitando o surgimento de padrões de operação

10 Estado de origem significa o Estado no território, no qual há o risco de dano transfronteiriço significativo ou sobre o qual tem jurisdição ou controle sobre qualquer outro lugar onde haja tal risco. Tradução nossa da terminologia definida no document original em inglês: "Draft on Articles on Prevention from Hazardous Activities, with commentaries, 2001" (INTERNATIONAL LAW COMMISSION, 2001). 
diferenciados e mesmo à sua inexistência dentro e entre os Estados.

A evolução da regulamentação internacional de meio ambiente, abrangendo a regulamentação da conduta das empresas multinacionais, aliada à devida responsabilização do Estado sede da empresa multinacional em caso de danos transnacionais, contribuiria para o avanço da adoção de padrões de qualidade ambiental suficientes para assegurar a prevenção de acidentes e danos ambientais significativos.

\subsection{Principais questões a serem analisadas}

A regulamentação internacional ambiental engloba tanto as normas juridicamente vinculantes, como as provenientes de tratados e convenções; o direito costumeiro, como as oriundas de instrumentos internacionais de caráter voluntário, como declarações e resoluções das Organizações das Nações Unidas e iniciativas privadas que buscam endereçar a responsabilidade corporativa.

Ambas regulamentações coadunam o propósito de garantir a proteção ambiental, sendo que as normas e práticas de responsabilidade corporativa ensejam apenas iniciativas voluntárias por parte das empresas, enquanto a regulamentação internacional ambiental aplica-se aos Estados.

O Direito Internacional responde ao desafio inerente ao dano ambiental transfronteiriço com imputação de responsabilidade ao Estado que causou o dano, sobre o qual pode-se citar o caso Gabcíkovo-Nagymaros, por meio do qual se estabeleceu a responsabilização internacional dos Estados por danos ambientais transfronteiriços.

Ao se estudar a responsabilização do Estado sede da empresa multinacional, entende-se que tal Estado admite os riscos decorrentes das atividades extraterritoriais de suas empresas por meio da extensão do princípio poluidor-pagador adotado na Conferência das Nações Unidas sobre o Meio Ambiente e Desenvolvimento, 1992, mediante as vantagens advindas pelo recolhimento de divisas, criação de mercador exportador, dentre outras. 
Analisar-se-á a possibilidade da responsabilização do Estado, por ação ou omissão, conforme prevista pela Comissão de Direito Internacional no Projeto de Artigos sobre a Responsabilidade dos Estados por Atos Ilícitos11, independente do Estado sede da empresa multinacional ser ou não o seu proprietário. Tal posicionamento do Direito Internacional promove maior comprometimento dos Estados em relação ao enquadramento da responsabilidade do Estado por ato internacionalmente ilícito e ao dever de diligência dos Estados na prevenção, controle e punição cometidos por seus entes privados nos danos fronteiriços (BARROS, 2012).

Evidenciar-se-ão casos jurídicos onde o caráter extraterritorial do dano ambiental extrapola a jurisdição dos Estados de localização das empresas subsidiárias na responsabilização de empresas multinacionais, demonstrado pela tendência da prática jurisprudencial adotada pelas cortes dos Estados sede destas empresas em processar as empresas oriundas destes Estados por danos extraterritoriais, gerando novas interpretações jurídicas sobre questões de jurisprudência, como forma de garantir a reparação do danos.

Neste contexto, a prática jurisprudencial internacional tem considerado a proximidade da relação corporativa entre e empresa sede e determinada subsidiária estrangeira, apresentando-se como uma alternativa para preencher esta lacuna no Direito Internacional do Meio Ambiente.

Avaliar-se-á se tais jurisprudências contêm elementos que possam consubstanciar a adoção de normas juridicamente vinculantes aplicáveis aos Estados e, indiretamente, às empresas multinacionais. Sobre a existência de normas locais de alcance extraterritorial vale mencionar o anteprojeto de leiı em curso na Suíça que exclui a responsabilidade dos gestores, em desacordo com o que se postula com a inclusão do ecocídio como crime tipificado no Estatuto de Roma do Tribunal Penal Internacional , mas engloba a responsabilização das empresas multinacionais em casos de danos ambientais ocorridos no estrangeiro.

Em resposta à inexistência de regulamentações internacionais juridicamente vinculantes referentes à sua conduta ambiental, empresas multinacionais atuam por meio de associações para endereçarem seus interesses comerciais e econômicos, como a Câmara 
Internacional de Comércio, membro observador da ONU, bem como para atuar na promoção de práticas que contribuam para a adoção de práticas ambientais sustentáveis, com o Pacto Global da ONU. Sobre este aspecto, será analisada a tentativa de regulamentação da conduta das empresas multinacionais definida pelas Organizações das Nações Unidas.

A dificuldade da responsabilização do Estado sede da empresa multinacional por danos ambientais extraterritoriais causados pelas suas subsidiárias no exterior, bem como a falta de definição de padrões setoriais de operação globais os quais permitem que as empresas multinacionais adotem padrões menos restritivos adotados por seu Estado sede, seja na escolha de processos produtivos de fabricação com tecnologia defasada, como no uso de substâncias químicas de uso restrito e/ou proibido utilizados no Estado sede da empresa multinacional, acarretam desequilíbrios na qualidade ambiental entre os Estados.

Neste contexto, será analisado o caráter extraterritorial das normas de responsabilidade corporativa a fim de se detectar eventuais aderências e similaridades entre as normas vinculantes, jurisprudências e as normas de responsabilidade corporativa.

A fim de avaliar de forma consistente os aspectos relevantes da regulamentação internacional concernente à responsabilidade das empresas multinacionais por danos transnacionais, torna-se necessário também considerar a relação entre as normas de Direito Internacional do Meio Ambiente e de Direitos Humanos - dois ramos do Direito que partilham elementos significativos. Tal análise faz-se necessária ao se considerar convenções internacionais de Direitos Humanos que consideram a proteção ao meio ambiente como um direito humano, as quais contêm elementos que contribuem a responsabilização dos Estados por danos ambientais extraterritoriais.

Será também analisada a possibilidade da inclusão do ecocídio - crime que designa a destruição do meio ambiente em larga escala como crime contra a humanidade no Estatuto de Roma do Tribunal Penal Internacional, o que permitiria às vítimas acionar em nível internacional os possíveis autores do crime, sejam empresas ou chefes de Estado e autoridades, para a obtenção de indenizações por danos morais ou econômicos, sendo que a responsabilidade direta e penas de prisão poderão ser emitidas sob condições específicas.

Mediante o acima exposto, analisar-se-á o papel da atual regulamentação internacional de meio ambiente, incluindo a responsabilidade corporativa, na promoção de normas que visem a responsabilização dos Estados por danos ambientais extraterritoriais causados por empresas multinacionais sediadas em seu território no exterior. 


\subsection{Metodologia}

A metodologia aplicada baseia-se prioritariamente em procedimentos instrumentais que viabilizem a obtenção de informações referentes à regulamentação internacional ambiental e de responsabilidade corporativa que envolvam empresas multinacionais em casos de dano transnacional.

Serão estudadas as doutrinas nacionais e internacionais sobre o tema, bem como serão objeto de estudo os tratados e convenções, protocolos e tratados sobre o tema elaborados por organismos internacionais e associações empresariais.

Dentre os materiais analisados para elaboração da dissertação, destacam-se os principais julgados de processos envolvendo disputas ambientais, cujos andamentos e sentenças estão disponíveis em bases de dados dos tribunais e cortes onde os processos foram tramitados.

Serão consultados materiais bibliográficos 13, como fontes primárias, artigos científicos publicados em periódicos disponíveis nos bancos de dados da Faculdade de Direito da Universidade de São Paulo, sites de organizações internacionais e intergovernamentais que versem sobre temas correlatos ao tema da dissertação, bem como sites corporativos de empresas multinacionais.

Também serão consultadas fontes de organizações internacionais, associações e iniciativas internacionais, centros de pesquisa e agências especializadas.

13 Para a elaboração das referências constantes na presente dissertação será utilizada a norma ABNT 6023 (ASSOCIAÇÃO BRASILEIRA DE NORMAS TÉCNICAS, 2018) conforme a recomendação constante nas Diretrizes para apresentação e dissertações e teses da USP, 3 Ed., 2016 (FUNARO, DZIABAS, et al., 2016). 


\section{CONCLUSÃO}

O presente estudo buscou avaliar a contribuição das normas internacionais para a proteção ambiental - mandatórias ou voluntárias - sob o aspecto da responsabilização das empresas multinacionais por danos transnacionais, sobre o qual foi possível concluir os entendimentos descritos a seguir.

A regulamentação internacional do meio ambiente tem apresentado uma evolução notável em relação à definição de recomendações aos Estados, estabelecendo regulamentações em nível internacional - ainda que voluntárias - as quais preveem medidas de proteção ambiental, inclusive de alcance extraterritorial; adicionalmente às normas obrigatórias, como as evidenciadas em tratados, acordos e convenções citadas neste estudo.

As normas de RSC tem-se apresentado também como uma alternativa às normas internacionais juridicamente vinculantes adotadas por empresas multinacionais; seja por meio iniciativas desenvolvidas no âmbito das Organizações das Nações Unidas e por declarações provenientes de conferências internacionais, principalmente; seja por iniciativas intergovernamentais; seja por meio de iniciativas de associações empresariais e outras instituições; todas contribuindo para a emergência de princípios legais que poderão ser inclusos em futuros instrumentos internacionais.

Tais iniciativas são baseadas em recomendações contidas em princípios e guias orientadores incluindo os mais diversos temas de RSC, tais como: mudança climática, água, trabalho infantil, cadeia de suprimentos, energia, dentre outros que se apresentam como desafios para a gestão responsável de empresas. Entretanto, não possuem qualquer valor jurídico ou que exija uma verificação independente por uma terceira parte, como ocorre com a certificação de sistemas de gestão de normas ambientais e com a asseguração dos relatórios de sustentabilidade.

Os desafios inerentes à regulamentação internacional ambiental apresentam caminhos para a responsabilização e conduta tanto dos Estados quanto das empresas multinacionais, considerando-se as limitações dos Estados devido aos possíveis conflitos de jurisdição relacionadas à regulamentação extraterritorial de RSC, sendo esta ainda mais dificultada devido à aplicação do princípio da não-intervenção, o qual apresenta-se como 
um fator limitante à atuação do Estado sede das empresas multinacionais em legislar extraterritorialmente em relação às normas de RSC - mais precisamente - em relação a proteção ambiental.

De fato, nota-se uma desconexão entre o comportamento adotados pelos órgãos judiciais nacionais de Estados sede de empresas multinacionais localizadas em Estados aderentes ao Direito Comum, como Reino Unido e Austrália, as quais têm aceito sediar o julgamento destas empresas em caso de danos ambientais transnacionais, os quais envolvem a responsabilização direta das empresas sede em detrimento da responsabilização das suas empresas subsidiárias em órgãos judiciais dos Estados nos quais operam.

Embora a Suprema Corte dos Estados Unidos da América tenha se pronunciado contra a tramitação de casos contra empresas estadunidenses por violações de Direitos Humanos cometidos no estrangeiro por meio da Lei de Atos Ilícitos no Exterior; não o proibiu totalmente, permitindo que o processo possa ser aceito com a devida aprovação do Congresso dos Estados Unidos da América.

A atuação dos órgãos jurídicos nacionais é a única forma de imposição de obrigações para as empresas multinacionais em caso de violações de direitos humanos e de meio ambiente e, espera-se que as decisões tomadas para a responsabilização das empresas sede das empresas multinacionais em relação aos impactos negativos causados por suas empresas subsidiárias possam influenciar o desenvolvimento do Direito Internacional de RSC, embora estes casos tenham como base a alegação de negligência e não a violação de alguma norma internacional.

Entretanto, o Direito Internacional ao absorver temas do Direito Interno, como os padrões de meio ambiente ou do trabalho, determina o correspondente encolhimento do “domínio reservado" do Estado.

Vale ressaltar a recente iniciativa de empresas alemãs para a elaboração de uma legislação para estabelecer obrigações diretas às empresas alemãs perante o dever de proteção (“due diligence”) aplicáveis às suas empresas subsidiárias no estrangeiro. Tem-se, neste caso, uma falta de sintonia entre as empresas multinacionais que preferem iniciativas voluntárias e outras que reconhecem a necessidade da existência de normas juridicamente vinculantes para garantir a efetiva proteção ambiental e igualdade de condições competitivas em nível global.

A Organização das Nações Unidas, após o fracasso de sua tentativa em estabelecer obrigações diretas para as empresas multinacionais por meio do Projeto de 
Código de Conduta para Corporações Transnacionais, tem discutido atualmente o projeto de um instrumento jurídico para regulamentar no Direito Internacional de Direitos Humanos, as atividades de empresas transnacionais e outros empreendimentos de negócios.

Embora notável por contemplar contribuições de outros atores - além dos Estados e das organizações internacionais - e por incluir aspectos de proteção ambiental, reiterando o entendimento sobre a interconexão entre o Direito Internacional dos Direitos Humanos e do Direito Internacional do Meio Ambiente; todavia, não propõe a adoção de obrigações extraterritoriais para os Estados sede de empresas multinacionais, como as apresentadas nos Princípios de Maastricht.

Em termos gerais, tais obrigações são justificáveis pela importância econômica e influência política exercida pelas empresas multinacionais, além de sua capacidade de afetar os direitos humanos e a qualidade do meio ambiente devido aos riscos e impactos inerentes às suas atividades.

A inclusão do ecocídio no Tratado de Roma apresenta-se como uma alternativa para a responsabilização de representantes da alta administração das empresas multinacionais no âmbito do Direito Internacional por crimes ambientais decorrentes das operações das empresas sob sua gestão. Salienta-se, no entanto, a dificuldade inerente à alteração de um acordo internacional.

A tensão existente entre o ganho econômico e a proteção ambiental poderia ser resolvida se maiores esforços fossem dispendidos no estabelecimento de medidas embasadas na coerente aplicação dos princípios da prevenção e do dever de proteger, em detrimento da distribuição e deslocalização de indústrias perigosas visando resultados econômicos no curto prazo.

Conforme discutido, uma série de iniciativas têm sido definidas em nível internacional para o estabelecimento de obrigações de RSC para as empresas multinacionais, principalmente em países em desenvolvimento que recebem as empresas subsidiárias das empresas multinacionais, as quais, em sua grande maioria, caracterizando-se como normas voluntárias; todavia podendo influenciar o surgimento de obrigações internacionais de meio ambiente, considerando-se sua relação com o Direito Internacional de Direitos Humanos.

Importante observar que quanto mais semelhante forem as legislações nacionais ambientais às normas internacionais de meio ambiente, menos suscetível estará o Estado de localização das empresas subsidiárias aos duplos padrões de qualidade ambiental eventualmente determinados pelas empresas sede. E, sob o aspecto jurídico, torna-se mais 
difícil corroborar o argumento de que o seu atendimento é somente uma questão de jurisdição interna do Estado.

A adoção de práticas responsáveis pelas empresas multinacionais independe de regulamentação internacional obrigatória, haja vista a receptividade das empresas multinacionais às normas de responsabilidade social corporativa voluntárias, haja vista que no âmbito do comércio internacional, o estabelecimento de padrões mínimos de meio ambiente é considerado como uma forma de protecionismo por parte dos países desenvolvidos em relação aos países menos desenvolvidos, os quais apresentam, por vezes, um ambiente regulatório deficiente ou ainda, com interesses econômicos que sobreponham aos interesses de proteção ambiental.

O desenvolvimento de padrões mínimos de RSC não tem sofrido oposição dos países em desenvolvimento por não apresentarem custos e nem exigências que possam limitar suas fontes de "vantagem comparativa". De fato, o presente trabalho demonstrou que a maioria das iniciativas de regulamentação tem como origem os Estados sede das empresas multinacionais, os quais absorvem tanto o seu custo político quanto econômico.

Relevante mencionar que à exceção do Companies Act 2013109, Índia, não foi diagnosticado no presente trabalho outra regulamentação de RSC relevante por parte de países em desenvolvimento e menos desenvolvidos; contrariamente ao que poderia se esperar, considerando-se que as atividades perigosas desenvolvidas por empresas multinacionais localizam-se neste países e que sua contribuição para o desenvolvimento de futuras normas internacionais de RSC poderia ser estimulada.

As discussões sobre a responsabilização de empresas multinacionais por atividades perigosas desenvolvidas no exterior, talvez incentive a mudança de comportamento das empresas multinacionais em relação a adoção de duplos padrões de qualidade ambiental, ao verificarem que em caso de violações em casos de danos ambientais transnacionais, sua responsabilização pode ocorrer, se não em cortes internacionais e locais; nas cortes dos Estados sediam suas sedes estatutárias.

Embora tal cenário possa descrever um caminho sem alternativa para as empresas multinacionais (o que poderia explicar a recente iniciativa de regulamentação extraterritorial fomentada por algumas empresas alemãs) as pressões de mercado em relação à reputação da gestão ambiental destas empresas, questões de mercado e até certo ponto, 
morais, por parte dos gestores empresariais; podem contribuir para a sustentabilidade das empresas no mercado global.

Por fim, o presente estudo demonstra que o Direito Internacional do Meio Ambiente e a responsabilidade corporativa podem caminhar em direção à definição de normas juridicamente vinculantes, as quais possivelmente serão influenciados pelas iniciativas de regulamentação extraterritorial oriundas dos Estados sede de empresas multinacionais, seja por meio de legislações - o que apresenta-se ainda controverso devido aos desafios perante à soberania, jurisdição e princípio da não intervenção - seja por meio de seus órgãos judiciais nacionais; sejam por iniciativas empresariais, as quais mesmo que apresentem-se incipientes, parecem direcionar seus esforços para a elaboração de normas juridicamente vinculantes para assegurar a devida proteção ambiental em nível global. 


\section{REFERÊNCIAS BIBLIOGRÁFICAS}

\section{LIVROS}

BAKAN, J. The Corporation: the pathological pursuit of profit and power. New York: Free Press, 2004.

BALDWIN, R.; CAVE, M.; LODGE, M. Understanding Regulation: Theory, Strategy, and Practice. 2nd Edition. Oxford: Oxford University Press, 2012.

BARROS, A. S. Multinacionais e a deslocalização de indústrias perigosas. $1^{\text {a }}$ edição. ed. Coimbra: Coimbra Editora, 2012.

BINGHAM, L. T. The Rule of Law in the International Order. Grotius Lecture of the British Institute of International and Comparative Law. London: [s.n.]. 2008.

Disponível em: < https://www.biicl.org/newsitems/109/lord-bingham-delivers-annualgrotius-lecture-on-the-rule-of-law-in-the-international-order

>. Acesso em: 11 dez. 2019.

BIRNIE, P. W.; E., A.; REDGWELL, C. International Law \& the Environment.3 rd Edition. ed. Oxford: Oxford Press University, 2012.

BIRNIE, P.; BOYLE, A. International Law and the Environment. 2nd Edition. ed. Oxford: Oxford University Press, 2002.

BORN, G. International Civil Litigation in United States Courts. 5. ${ }^{\text {a }}$ ed. New York: Wolters Kluwer Law \& Business, 2011. Disponível em: < https://www.amazon.com/dp/B0091JAU88/ref=rdr_kindle_ext_tmb>. Acesso em: 27 nov. 2019.

CLAPP, J. The Transfer of Hazardous Wastes from tich to Poor Countries. London: Cornell University Press, 2001.

COLLERIDGE, Samuel T. Coleridge's Ancient Mariner and Selected Poems. New York: Columbia University, 1908.

DICKENS, C. Tempos difíceis. [S.1.]: Ed. Bomtempo, 1976.

DINE, J. The governance of corporate groups. Cambridge: Cambridge University Press, 2000.

ECONOMY, E. C.; MICHAEL, L. By All Means Necessary: How China's resource quest is changing the world. New York: Oxford University Press, 2014. 
ELKINGTON, J. Cannibals with Forks: The Triple Botton Line of 21st Century Business. Oxford: Capstone Publishing, 1997.

GOBBELS, M. Reframing Corporate Social Responsibility: The Contemporary Conception of a Fuzzy Notion. Rotterdam: Erasmus University Rotterdam, 2002.

HANDL, Gunther. Transboundary Impacts, p. 532-549, in Daniel Bodanski, Jutta Brunee and Ellen Hey, The Oxford Handbook of International Environmental Law. Oxford: Oxford University Press, 2007.

HANKIN, X. Transboundary Damage in International Law. Cambridge: Cambridge University Press, 2003.

HIGGINS, P. Eradicating ecocide. 2nd. ed. London: Shefeard -Walwyn Ltd, 2015.

HIGGINS, R. Problems and Process: International Law and How We Use it. Oxford: Clarendon Press, 2004.

HOOD, J. M. The Heroic Enterprise: Business and the Common Good. New York: Free Press, 1996. p.xv.

HOPKINS, M. Corporate Social Responsibilty \& International Development: are corporations the solution? Oxfordshire: Earthscan, 2009.

JOSEPH, S. Corporations and Transnational Humans Rights Litigation. Oxford : Hart Publishing, 2004.

KAMMINGA, M. T. Extraterritoriality. Oxford Public International Law. Oxford. 2012.Disponível em: https://opil.ouplaw.com/view/10.1093/law:epil/9780199231690/law9780199231690e1040>. Acesso em: 14 nov. 2019.

KIRSCH, S. Mining Capitalism: The Relationship between Corporations and Their Critics. Oakland: University of California Press, 2014.

LOW, N.; GLEESON, B. Justice, Society and Nature: An exploration of political ecology. New York: Routledge, 1998.

PELlOW, D. N. Resisting Global Toxics: Transnational Movements for Environmental Justice. Boston: MIT Press, 2007.

ROCKSTROM, J.; KLUM, M. Big World Small Planet: abundance within planetary boundaries. New Haven: Yale University Press, 2015.

SANDS, P.; PEEL, J. Principles of International Environmental Law. Cambridge: Cambridge University Press, 514 p., 2012.

SKOGLY, S. L. Beyond National Borders: States Human Rights Obligations in International Cooperation. Oxford: Intersentia, 2006. 
SOARES, G. F. S. Direito Internacional do Meio Ambiente: Emergência, Obrigações e Responsabilidades. São Paulo: Editora Atlas, 2001.

SORNARAJAH, M. Linking State Responsibility for Certain Harms Caused By Corporate Nationals Abroad to Civil Recourse in the Legal Systems of Home States. In: SCOTT, C. Torture as Tort - comparative perspectives on the development of transnational human rights litigation. Oxford: Hart Publishing, p. 491-512, 2001.

STONE, D. C. Should trees have standing? Law, morality abd the environment. 3rd Edition. ed. New York: Oxford University Press, 2012.

UTTING, P.; MARQUES, J. C. Corporate Social Responsibility and Regulatory Governance: Towards Inclusive Development? Hampshire: Palgrave Macmillan, 2010 .

VOGEL, D. The Market for Virtue: The Potential and Limits of Corporate Social Responsibility. 2nd. ed. Washington: Brookings, 2005.

VOTAW, D.; SETHI, S. P. The Corporate Dilemma: Tradicional Values versus Contemporary Problems. New York: Prentice Hall, 1973.

WALKER, G. Environmental Justice: Concepts, evidence and politics. New York: Routledge, 2012.

WELlinG, B. Corporate Law in Canada. Toronto: Butterworths, 1991.

WIRTH, Daniel A. Hazardous Substances and Activities, p. 399-422, in Daniel Bodanski, Jutta Brunee and Ellen Hey, The Oxford Handbook of International Environmental Law. Oxford: Oxford University Press, 2007.

WOOD, D. J. et al. Global Business Citizenship: A Transformative Framework for Ethics and Sustainable Capitalism. Armonk: M.E. Sharp, 2006.

ZADEK, S. The Civil Corporation. London: Earthscan, 2001.

ZERK, J. A. Multinationals and Corporate Social Responsibility Limitations and Opportunities in International Law. New York: Cambridge University Press, 2011. 


\section{REVISTAS JURÍDICAS E ARTIGOS ELETRÔNICOS}

ANDERSON, M. Transnational Corporations and Environmental Damage: Is Tort Law the Answer? Washburn Law Journal , v. 41, n. 3, p. 399-426, 2002.

AUGENSTEIN, D. Torture as Tort? Transnational Tort Litigation for CorporateRelated Human Rights Violations and the Human Right to a Remedy. Human Rights Law Review, Oxford, v. 18, p. 593-612, 2018.

BUSINESS \& HUMAN RIGHTS RESOURCE CENTRE. A call for mandatory human rights and environmental due diligence legislation. [S.I.] 2019. Disponível em: <https://www.business-humanrights.org/en/german-businesses-call-for-legalduty-of-care-for-human-rights-and-the-environment>. Acesso em: $11 \mathrm{dez} .2019$.

German businesses call for legal duty of care for human rights and the environment. [S.I.] 2019. Disponível em: <https://www.businesshumanrights.org/en/german-businesses-call-for-legal-duty-of-care-for-human-rightsand-the-environment>. Acesso em: $16 \mathrm{dez} .2019$.

List of large business, associations \& investors with public statements \& endorsements in support of human rights due diligence regulation. [S.I.] 2019. https://www.business-humanrights.org/en/list-of-large-businesses-associationsinvestors-with-public-statements-endorsements-in-support-of-human-rights-duediligence-regulation >. Acesso em: 16 dez. 2019.

Supreme Court to decide whether corporations can be sued over complicity in human rights abuse abroad. Out. 2018. Disponível em: < https://www.business-humanrights.org/en/usa-supreme-court-to-decide-whethercorporations-can-be-sued-over-complicity-in-human-rights-abuses-abroad>. Acesso em: 16 nov. 2019.

CARROL, A. B. A three-dimensional conceptual model of corporate performance. Academy of Management, v. 4, p. 497-505, 1979.

CARROL, A. B. The pyramid of corporate social responsibility: toward the moral management of organisation stakeholder. Business Horizons, v. 34, p. 39-48, 1991.

CHINKIN, C. M. The Challenge of Soft Law: Develpment and Change in International Law. The International and Comparative Law Quaterly, v. 38, n. 4, p. 865-866, 1989. 
CLOUGH, J. Not-so-innocents abroad: corporate criminal liability for human rights abuses. Australian Journal of Human Rights, v. 11, n. 1, p. 1-32, 2005.

DAMROSCH, L. F. Politics Across Borders: Nonintervention and Nonforcible Influence over Domestic Affairs. The American Journal of International Law, v. 3, n. 1, p. 1-50, 1989.

DE FEYTER, K. International Human Rights Law in a Global Context. In: DE FEYTER, K.; GOMEZ, I. F. Globalisation and Human Rights. Bilbao: University of Deusto, p. 51-96, 2009.

DE SCHUTTER, O. et al. Commentary to the Maastricht on Extraterritorial Obligations of States in the Area of Economic, Social and Cultural Rights. Human Rights Quarterly, Baltimore, 2012.

EASTERBROOK, F. H.; FISCHEL, D. R. Antitrust Suits by Targets of Tender Offers. Michigan Law Review, v. 80, p. 1155-1178, 1982. Disponível em: < https://chicagounbound.uchicago.edu/cgi/viewcontent.cgi?article $=2168 \&$ context $=$ jou rnal_articles >. Acesso em: 10 dez. 2019.

EMMERIJ, L.; JOLLY, R. The UN and Transnational Corporations. Briefing Note, New York, v. 17, p. 5, 2009.

FLEURS, J. The Invisibility of the Transnational Corporation: an Analysis of Internationa Law and Legal Theory. Melbourne University Law Review 893. Melbourne, p. 893-923, 1994.

FORCESE, C. ATCA's Achilles Heel: Corporate Complicity, International Law and the Alien Tort Claims Act. Yale Journal of International Law, v. 26, n. 2, p. 487515, 2001. Disponível em:< https://digitalcommons.law.yale.edu/cgi/viewcontent.cgi?article $=1152 \&$ context=yjil >. Acesso em: 7 dez. 2019.

FRANCIONI, F. Exporting Environmental Hazard through Multinational Enterprises: Can the State of Origin be held Responsible ? In: FRANCIONI, F.; SCOVAZZI, T. International Responsibility for Environmental Harm. Londres: Graham \& Trotman, v. 14, p. 275-298,1991.

FREEMAN, I.; HASNAOUI, A. The meaning od corporate social responsibility: the vision of four nations. Journal of Business Ethics, v. 3, n. 100, p. 419-443, 2011.

FRIEDMAN, M. The Social Responsibility of Business is to Increase its Profits. The New York Times, New York, Sep. 13, 1970. Disponível em: http://umich.edu/ thecore/doc/Friedman.pdf. Acesso em: 7 dez. 2019.

FRYNAS, J. G. Corporate Social Responsibility or Goverment Regulation? Evidence on Oil Spill Prevention. Ecology and Society, v. 17, n. 4, 2012.

GUNNINGHAM, N. Shaping corporate environmental performance: a review. Environmental Policy and Governance, v. 19, n. 4, p. 215-231, 2009. 
HARLOW, C. Public and Private Law: Definition without Distinction. Modern Law Review, v. 43, n. 3, p. 241-265,1980.

HEYVAERT, V. Regulatory Competition-Accounting For the Transnational Dimension of Environmental Regulation. Journal of Environmental Law, v. 25, n. 1, p. 1-31, 2013.

HYLTON, K. N. When Should We Prefer Tort Law to Environmental Regulation. Washburn Law Journal, v. 41, n. 3, p. 515-534, 2002.

KING, A.; LENOX, M. Exploring the locus of profitable reduction. Management Science, 48, 289-299, 2002.

JAPHET, K.; TAVIAH, V. K.; BENJAMIN, M. Debate on Mandatory Corporate Social Responsibility. Conference Paper presented at National Seminar on Strategies for Business Excellence in Global Era. [S.1.]: [s.n.]. 2015. https://www.researchgate.net/publication/315434861_Debate_on_Mandatory_Corpo rate_Social_Responsibility. Acesso em: 31 out. 2019.

KINLEY, DAVID; TADAKI, JUNKO. From Talk to Walk: The Emergence of Human Rights Responsibilities for Corporations at International Law. Virginia Journal of International Law, v. 44, n. 4, p. 946, 2004.

KNOX, J. H. The Myth and Reality of Transboundary Environmental Impact Assessment. The American Journal of International Law, v. 96, n. 2, p. 291-319, April 2002. Disponível em:< https://www.jstor.org/stable/pdf/2693925.pdf?refreqid=excelsior\%3A7e776599b6b9 602b1620780fdcd8969c>. Acesso em: 19 nov. 2019.

MARCUSS, S. J. Jurisdiction with Respect to Foreign Branches and Subsidiaries: Judicial Power in the Foreign Affairs Context Under Section 414 of the Foreign Relations Restatement. The International Lawyer, v. 26, n. 1, p. 1-20, 1992.

Disponível em: <https://www.jstor.org/stable/pdf/40706939.pdf?refreqid=excelsior\%3Aa226d6c1f2 94a1d9f9874a99a9b59d21 >. Acesso em: 15 nov. 2019.

MARREWIJK, M. V. Concepts and Definitions of CSR and Corporate Sustainability - between agency and communionn. Journal of Business Ethics, v. 44, p. 95-105, 2002.

MATTEN, D.; MOON, J. "Implicit "and "explicit" CSR: a conceptual framework for a comparative understanding of corporate social responsibility. Academic of Journal Review, v. 2, n. 33, p. 404-424, 2008.

MCLACHLAN, C. The Influence of International Law on Civil Jurisdiction, Hague Yearbook of International Law, v. 6, p. 125-144, 1993.

MOLINA-AZORIN, J. F.; CLAVER-CORTES, E.; LOPEZ-GAMERO, M. D. Qualiy management, environmental management and firm performance: a review of empirical 
studies and issues of integration. International Journal of Management Reviews, 11, n. 2, 197-222, 2009.

MULligAN, S. P. The Rise and Decline of the Alien Tort Statute. Congressional Research Service. Washington, p. 3, 2018.

OLMSTEAD, C. J. Jurisdiction. Yale Journal of International Law, v. 14, n. 2, p. 468-488, 1989.

PAUL, J. R. Comity in international Law. Harvard international Law, v. 32, n. 1, p. $1-80,1991$.

PICCIOTTO, S. Reconceptualing Regulation in the Era of Globalization. Journal of Law and Society, v. 29, n. 1, p. 1-11, 2002.

ROTH, P. M. Reasonable Extraterritoriality: correcting the "balance of interests". International and Comparative Law Quaterly, v. 41, n. 2, p. 245-286, Apr 1992. Disponível em: < https://www.jstor.org/stable/pdf/760921.pdf?ab_segments=0\%252Fbasic_expensive $\% 252$ Fcontrol\&refreqid=excelsior\%3A573d3e625404b3361b4e2f371db75a7f $>$. Acesso em: 18 nov. 2019.

SAUVANT, K. P. The Negotiations of the United Nations Code of Conduct on Transnational Corporations: Experience and Lessons Learned. The Journal of World Investment \& Trade, New York, v. 16, p. 11-87, 2015.

SCHACHTER, O. The Emergence of International Environmental Law. Journal of International Affairs, v. 44, n. 2, p. 457-493, 1991.

SCHERER, A.; SMID, M. The Downward Spiral and the U.S. Model Business Principles - Why MNEs Should Take Responsibility for the Improvement of WorldWide Social and Environmental Conditions. Management International Review, v. 40, n. 4, p. 351-371, 2000. Disponível em: <https://papers.ssrn.com/sol3/papers.cfm?abstract_id=971056>. Acesso em: 19 nov. 2019.

SECK, S. L. Environmental Harm in Developing Countries Caused by Subsidiaries of Canadian Mining Corporations: The Interface of Public and Private International Law. The Canadian Yearbook of International Law, v. 37, p. 139-221, 1999.

SECK, S. L. Home State Obligations for the Prevention and Remediation of Transnational Harm: Canada, Global Mining and Local Communities. Osgoode Hall Law School - York University. [S.1.], p. 605. 2008. Disponível em: < https://papers.ssrn.com/sol3/papers.cfm?abstract_id=2126439>. Acesso em: 19 nov. 2019.

SHELTON, D. Human Rights and the Environment: what specific environmental rights have been recognized? Denver Journal of International Law and Policy, Denver, v. 35, p. 129-171, 2001. 
SMIS, S.; VAN DER BORGHT, K. Belgian Law concerning The Punishment of Grave Breaches of International Humanitarian Law: A Contested Law with Uncontested Objectives. American Society of International Law, v. 8, n. 18, July 2003. Disponível em: < https://www.asil.org/insights/volume/8/issue/18/belgian-lawconcerning-punishment-grave-breaches-international >. Acesso em: 19 nov. 2019.

STEPHENS, B. Upsetting Checks and Balances: The Bush Adminstration's Efforts to limit Human Rughts Litigation. Harvard Human Rights Journal , v. 169, 2004.

TRINDADE, A. C. The Domestic Jurisdiction os States in the Practice of the United Nations and Regional Organisations. International and Comparative Law Quaterly, v. 25, n. 4, p. 715-765, 1976. Disponível em:< https://www.jstor.org/stable/pdf/758523.pdf?refreqid=excelsior\%3A44da02f4297d7c 6b658ff26b960450bf >. Acesso em: 1 dez. 2019.

TZEVELEKOS, V. P. In Search of Alternative Solutions: Can the State od Origin be Held Internationally Responsible for Investors Human Rights Abuses that are not Attributable to it. Brooklyn Journal of International Law, v. 35, p. 155-231, 2010.

WARD, H. Governing Multinationals: The Role of Foreign Direct Liability. The Royal Institute of International Affais Energy and Environment Programme, v. 18, p. 1-6, February 2001.

WARREN, M. Corporate Structures, the Veil and the Role of the Courts. Melbourne University Law Review, Melbourne, v. 40, p. 658-687, 2016. Disponível em: <https://law.unimelb.edu.au/_data/assets/pdf_file/0008/2369591/07-Warren-402Post-Press.pdf >. Acesso em: 19 nov. 2019.

WEERAMANTRY, C. G. Human Rights and the Global Marketplace. Brooklyn Journal of International Law, New York, v. 25, n. 1, p. 27-50, 1999. 


\section{JURISPRUDÊNCIA}

AFRICAN COMMISSION ON HUMAN AND PEOPLE'S RIGHTS.

Social and Economic Rights Action Center v. Nigeria - Caso Ogoniland. Case N. ${ }^{\circ}$ ACHPR/COMM/A044/1, 27 de maio de 2002. Disponível em: < https://www.escrnet.org/caselaw/2006/social-and-economic-rights-action-center-center-economicand-social-rights-v-nigeria >. Acesso em: 9 jan.2020.

ALABAMA CLAIMS ARBITRATION. United States v. United Kingdom. [ S.I.] Geneva, 1872.

UK COURT OF APPEAL (Civil Division). Case Moses Fan Sithole \& Others v. Thor Chemicals Holdings Ltd. 2000 WL 142183.

Community on the Amendments of 22 June 1982 to the U.S. Exports

Regulation. US-EC disputes over the gas pipeline from Siberia to Webstern Europe. European Community News n.o 23/1982. Washington DC, 1982. Disponível em: < http://aei.pitt.edu/1768/1/US_dispute_comments_1982.pdf >. Acesso em: 16 nov. 2019.

EUROPEAN COURT OF HUMAN RIGHTS. Case of Guerra and others v. Italy. (116/1996/735/932). Judgment 19 february 1998. Strasbourg, 1998.

Case of López Ostra v. Spain. (Application no. 16798/90). Strasbourg, 1994. Disponível em: <https://hudoc.echr.coe.int/eng\#\{"itemid":["001-57905"]\} >. Disponível em: 〈>. Acesso em: 9 jan.2020.

. Case of Powell e Rayner v. The United Kingdom. (Application no. 9310/81). Strasbourg, 1981. Disponível em: < https://hudoc.echr.coe.int/eng\#\{"itemid":["001-57622"]\}>. Acesso em: 9 jan.2020.

EUROPEAN COURT OF JUSTICE. Hydrotherm Gerätebau GmbH v. Compact del Dott. Ing. Mario Andreoli \& C. Sas. Case 170/83. [S.1.]. 1984. Disponível em: < https://eur-lex.europa.eu/legal-content/EN/TXT/?uri=CELEX\%3A61983CJ0170 >. Acesso em: 10 dez. 2019.

HOUSE OF LORDS. Case British South Africa Co. v. Companhia de Moçambique, 1983.[S.I.] Disponível em:< https://swarb.co.uk/british-south-africacompany-v-companhia-de-mocambique-hl-1893/ >. Acesso em: 27 nov. 2019.

Case Connely v. RTZ Corporation plc. $\{$ S.I. $\}$ 1998. Disponível em:<http://www.bailii.org/cgibin/markup.cgi?doc=/uk/cases/UKHL/1997/30.html\&q uery=Connelly+v+RTZ+Corporation+plc+\&method=all $>$. Acesso em: 9 jan.2020.

Case Hesperides Hotels Ltd. v. Muftizade, 1979. [S.I.]. Disponível em:< https://swarb.co.uk/hesperides-hotels-ltd-v-aegean-turkish-holidays-ltd-muftizahdehl-1978/ >. Acesso em: 27 nov. 2019. 
INTER-AMERICAN COURT OF HUMAN RIGHTS. Case of VelásquezRodríguez v. Honduras. Judgment of July 29, 1988 Merits. Washington, 1988. Disponível em: < http://www.corteidh.or.cr/docs/casos/articulos/seriec_04_ing.pdf>. Acesso em: 9 jan. 2020.

INTERNATIONAL COURT OF JUSTICE. Anglo-Norwegian Fisheries Case ( UK v. Norway). International Court of Justice. [S.1.], p. Reps. 166. The Hague.1951.

Asylum Case (Columbia v. Peru). International Court of Justice. [S.1.], p. Reps 266, 276-277. The Hague, 1950.

Case concerning the Barcelona Traction Light and Power Limited. Reports and judgements, advisory opinions and orders. INTERNACIONAL COURT OF JUSTICE. The Hague, p. 54. 1970.

. Gabcíkovo-Nagymaros Project Case (Hungria v. Tchecoslováquia). The Hague, 1997. Disponível em: < https://www.icj-cij.org/en/case/92>. Acesso em: 9 jan.2020.

Military and Paramilitary Activities in and against Nicaragua (Nicaragua v. United States of America). The Hague, 1986.

North Sea Continental Shelf Cases (Federal Republic of Germany v. Denmark; Federal Republic of Germany v. Netherlands). [S.1.], p. Reps. 3, 44. 19. The Hague, 1969.

Pulp Mills on the River Uruguay. (Argentina v. Uruguay). Summary of the Judgment of 20 April 2010.The Hague, 2010. Disponível em: < https://www.icjcij.org/en/case/135/summaries >. Acesso em: 9 jan. 2020.

Reports of Judgements, Advisory Opinions and Orders - Legality of the Threat or use of Nuclear Weapons. The Hague, 1996. Disponível em:< https://www.icj-cij.org/files/case-related/95/095-19960708-ADV-01-00-EN.pdf >. Acesso em: 19 nov.2019.

InTERnAtional CRIMINAl COURT. Policy Paper on Case of Selection and Priorization. International Criminal Court. Haia. 2016.

NSW COURT OF APPEAL. Case CSR v. Young. [S.I.] 1998.

SUPREME COURT OF INDIA. Union Carbide Corporation (Appellant) v. Union of India and others (Respondents). New Delhi, 1989.

SUPREME COURT OF THE UNITED STATES. Caso Jesner v. Arab Bank.. Washington, $\quad$ p. $\quad 34, \quad 2018 . \quad$ Disponível em:< https://www.supremecourt.gov/opinions/17pdf/16-499_new_7648.pdf >. Acesso em: 18 nov. 2019

SUPREME COURT OF VICTORIA. Case Dagi v BHP. 1995. [S.I]. 
. Case Gagarimabu (BHP) v Broken Hill Proprietary Co Ltd. and OK Tedi Mining Ltd], VSC 517 (21 December 2001). Disponível em: < http://www8.austlii.edu.au/cgibin/viewdoc/au/cases/vic/VSC/2001/517.html?stem=0 \&synonyms=0\&query=gagarimabu $>$. Acesso em: 9 jan. 2020.

THE COURT OF FIRST INSTANCE OF THE EUROPEAN COMMUNITIES. Gencor Ltd $\mathbf{v}$ Commission of the European Communities. THE COURT OF FIRST INSTANCE OF THE EUROPEAN COMMUNITIES. [S.1.]. 1999.

Disponível em:< https://eurlex.europa.eu/legalcontent/GA/TXT/?uri=CELEX:61996TJ0102>. Acesso em: 18 nov. 2019.

THE UNITED NATIONS HUMAN RIGHTS COMMITTEE. Bordes, Tauira e Temeharo v. France. Communication n. ${ }^{\circ}$ 645/1995, 22 de julho de 1996. Strasbourg, 1996. Disponível em: < http://www.corteidh.or.cr/tablas/23204.pdf>. Acesso em: 9 jan. 2020. at 20 (1984).

E. H. P. v. Canada. Communication No. 67/1980, U.N. Doc. CCPR/C/OP/1

UK COURT OF APPEAL. Case Lubbe v. Cape plc. London.2000. Disponível em:<http://www.bailii.org/cgibin/markup.cgi?doc=/ew/cases/EWCA/Civ/1998/1351. $\mathrm{html} \& q u e r y=$ Lubbe $+\mathrm{v}+\mathrm{Cape}+$ plc\&method=all $>$. Acesso em: 9 jan.2010

UK HIGH COURT. Jones v Lipman case law [1962] 1 WLR 832. UK High Court. [S.1.]. 1962.

UNITED NATIONS ORGANIZATION. INTERNATIONAL LAW COMISSION. Draft articles on Prevention of Transboundary Harm from Hazardous Activities, with commentaries, 2001. INTERNATIONAL LAW COMISSION. The Hague. 2001. Disponível em: < http://legal.un.org/ilc/texts/instruments/english/commentaries/9_7_2001.pdf>. Acesso em: 13 mai.2019.

. Draft articles on Responsibility of States for Internationally Wrongful Acts, with commentaries, 2001. The Hague. 2001.

Draft principles on the allocation of loss in the case of transboundary harm arising out of hazardous activities, with commentaries 2006. INTERNATIONAL LAW COMISSION. The Hague. 2006.Disponível em:〈https://legal.un.org/ilc/texts/instruments/english/commentaries/9_10_2006.pdf> . Acesso em: 2 Jan. 2020.

Yearbook of the International Law Commission, 1985, VOLUME II, PART ONE, Documents of the thirty-second session), p. 247 a 266. The Hague, $1985 . \quad$ Disponível em:< https://legal.un.org/ilc/publications/yearbooks/english/ilc_1985_v2_p1.pdf >. Acesso em: 9 jan. 2020. 
Yearbook of the International Law Commission Report of the Commission to the General Assembly on the work ofthe thirtieth sessionThe Hague. 1979.

UNITED STATES COURT OF APPEAL . Adams v. Cape industries plc [1990] Cn 433. Court of Appeal. [S.1.]. 1990.

United States v. Aluminum Co. of America. [S.I.]. Disponível em: < https://law.justia.com/cases/federal/appellate-courts/F2/148/416/1503668/

>. Acesso em: 18 nov. 2019.

UNITED STATES COURT OF APPEALS. Dolly M. E. Filartiga and Joel Filartiga, plaintiffs-Appellants 630 F. 2d 876. United States Court of Appeals, Second Circuit. Washington. 1980.

UNITED STATES DISTRICT COURT FOR THE SOUTHERN DISTRICT OF NEW YORK. Case Wiwa v. Royal Dutch Petrolium Co. New York, 2009.

\section{DOCUMENTOS INTERNACIONAIS}

AGEFI. Le Conseil national adopte un contre-project à l'initiative. 14 jun. 2018. Disponível em: < http://www.agefi.com/home/news/detailageficom/edition/online/article/le-conseil-national-est-entre-en-matiere-par-133voix-contre-64-pour-se-pencher-sur-la-revision-du-droit-des-multinationales477795.html>. Acesso em: 16 jul. 2018.

AMERICAN LAW INSTITUTE. US Third Restatement on Foreign Relations Law. AMERICAN LAW INSTITUTE. [S.1.]. 1987.

ASSOCIAÇÃO BRASILEIRA DE NORMAS TÉCNICAS. ABNT NBR 6023:2018 - Informação e documentação: referências: elaboração. Rio de Janeiro: 2 ed., 68p. 2018.

ASSOCIAÇÃO BRASILEIRA DE NORMAS TÉCNICAS. ABNT NBR ISO 14001:2015 Sistemas de gestão ambiental - Requisitos com orientações para uso. Associação Brasileira de Normas Técnicas. [S.1.], p. 41. 2015.

BBC. Shell pagará US\$ 15, 5 milhões por mortes de ativistas na Nigéria.9 jun. 2009. Disponível em:

https://www.bbc.com/portuguese/noticias/2009/06/090609_shellacordog . Acesso em: 6 ago.2019. 
COMMISSÃO ECONÔMICA PARA A EUROPA DAS NAÇÕES UNIDAS. Convenção da Comissão Econômica para a Europa das Nações Unidas (CEE/ONU) sobre Acesso à Informação, Participação do Público no Processo de Tomada de Decisão e Acesso à Justiça em Matéria de Ambiente - Convenção de Aarhus. Aarhus. 1998. Disponível em: < https://apambiente.pt/index.php?ref=16\&subref=142\&sub2ref=726\&sub3ref=727 >. Acesso em: 9 jan. 2020.

Convenção sobre a Avaliação dos Impactos Ambientais num Contexto Transfronteiriço - Convenção de Espoo. Espoo. 1991.

COMISSÃO ECONÔMICA PARA AMÉRICA LATINA E CARIBE. Acordo Regional sobre o Acesso à Informação, à Participação Pública e o Acesso à Justiça em Assuntos Ambientais. Comissão Econômica para América Latina e Caribe. Escazú. 2018.

COMISSÃO INTERNACIONAL DE DIREITOS HUMANOS. Protocolo adicional à Convenção Americana sobre Direitos Humanos em matéria de Direitos Econômicos, Sociais e Culturais, 28 ILM 156 (1989), de 17 de novembro de 1988, Artigo $11 .^{\circ}$, números 1 e 2 . Washington, 1988.

COMMISSION OF THE EUROPEAN COMMUNITIES. Green Paper: Promoting a european framework for corporate social responsibility. European Union. Bruxelles. 2001.

Communication from the Commission concerning Corporate Social Responsibility: A business contribution to Sustainable Development. Commission of the European Communities. Brussels, p. 24. 2002. Disponível em: < https://ec.europa.eu/europeaid/communication-commission-concerning-corporatesocial-responsibility-business-contribution_en >. Acesso em: 2 dez. 2019.

COMUNIDADE ECONÔMICA EUROPEIA. Convenção de Bruxelas de 1968 relativa à Competência Jurisdicional e à Execução de Decisões em matéria civil e comercial. Bruxelas. 1968. Disponível em:< https://eurlex.europa.eu/legalcontent/PT/TXT/PDF/?uri=CELEX:41968A0927(01)\&from=PT >. Acesso em: 26 nov. 2019.

ECOCIDE LAW. Relevant international crime history. Disponível em: < https://ecocidelaw.com/the-law/history/\#_ftn6>. [S.1.].Acesso em: 17 out. 2019.

EUROPEAN COMMISSION.European Multi-stakeholder Forum on CSR Final results \& recommendations. European Commission. Brussels. 2004. Disponível em: $<\quad$ https://www.businesseurope.eu/sites/buseur/files/media/imported/2004-01424EN.pdf >. Acesso em: 5 dez. 2019.

EUROPEAN COMMISSION. Comments on the Us Regulations Concerning Trade with the URSS. European Commisson. [S.1.]. 1982. 
EUROPEAN PARLIAMENT. Treaty establishing the European Community (Consolidated version 2002). European Parliament. [S.1.]. 2002. Disponível em: < https://eur-lex.europa.eu/legal-content/EN/TXT/?uri=CELEX\%3A12002E\%2FTXT >. Acesso em: 10 dez. 2019.

EXTRATERRITORIAL OBLIGATIONS CONSORTIUM.Maastricht Principles on Extraterritorial Obligations in the Area of Economic, Social and Cultural Rights. Heidelberg. 2013. Disponível em: < https://www.etoconsortium.org/nc/en/main-navigation/library/maastrichtprinciples/?tx_drblob_pi1\%5BdownloadUid\%5D=23>. Acesso em: 20.03.2019.

EXTRATIVE INDUSTRY TRANSPARENCE INITIATIVE 110(EITI).[S.I.] 2002. Disponível em: < https://eiti.org/who-we-are >. Acesso em: 4 dez. 2019.

EXTRATIVE INDUSTRY TRANSPARENCE INITIATIVE (EITI). The EITI Standard - The Global Standard for the Good Governance of Oil, gas and mineral resources. [S.I.] 2002. Disponível em: < https://eiti.org/standard/overview >. Acesso em: 4 dez. 2019.

FindLaw. Environmental liability disclosure and the Sarbanes-Oxley Act. [S.I.]. Disponível em: $<$ https://corporate.findlaw.com/law-library/environmental-liabilitydisclosure-and-the-sarbanes-oxley-act.html >. Acesso em: 1 nov. 2019.

FINLAND'S PRESIDENCY OF THE COUNCIL OF THE EU. Perspective Paper; Business and Human Rights - Towards a Common Agenda for Action. Perspective Paper; Business and Human Rights - Towards a Common Agenda for Action. Brussels: Finish Government. 2019. p. 49. Disponível em: < https://eu2019.fi/documents/11707387/15400298/EU2019FI+BHR+Conference+Per spectives+Paper/4e5ca42d-31ef-fff1-41c8-

aa0f $21 \mathrm{be} 17 \mathrm{ae} / \mathrm{EU} 2019 \mathrm{FI}+\mathrm{BHR}+\mathrm{Conference}+$ Perspectives+Paper.pdf

FORUM SHOPPING. Dicionário online Merriam-Webster. Disponível em: < https://www.merriam-webster.com/legal/forum\%20shopping >. Acesso em: 8 jan. 2020.

FRIENDS OF THE EARTH INTERNATIONAL. Towards Binding Corporate Accountability. Disponível em: $<$ https://friendsoftheearth.uk/sites/default/files/downloads/corporate_accountability.p df >. Acesso em: 06 nov. 2019.

FUNARO, V. M. B. O. et al. Diretrizes para apresentação de dissertações e teses da USP - Parte I (ABNT). 3a Edição. ed. São Paulo: Universidade de São Paulo, 2016.

FUNDAÇÃO DOM CABRAL. Licenciamento social. [S.I] [2013?]. Disponível em: $<$ http://www.institutoorior.com.br/images/artigospdf/raimundo/livro/temasemergentes/dimensao-sociedade/licenciamento-social.html>.Acesso em: $30 \mathrm{dez}$. 2018. 
GLOBAL REPORT INITIATIVE. GRI Contribution to Sustainable Development. Global Report Initiative. Amsterdam, p. 31, 2016.

GLOBAL WITNESS.Defenders of the Earth: Global killings of land and environmental defenders in 2016. Global Witness. London, p. 58, 2017. (ISBN 97841-911606-01-7).

Enemies of the State: How governments and business silent land and environment defenders. Global Witness. London, p. 58, 2019.

.Lessons Unlearned, Global Witness Report 2010: How the UN and Member States must do more to end natural resource-fuelled conflicts.[S.I.] 2010. London.

Global Witness Report 2010: How the UN and Member-States must do more to end natural resource-fuelled conflicts. Global Witness, 2010. Disponível em: < https://www.globalwitness.org/en/reports/lessons-unlearned/ >. Acesso em: 14 out. 2019.

HAUTALA, H. Business \& Human Rights Resource Centre. Business \& Human Rights Resource Centre web site, 2019. Disponível em: <https://www.businesshumanrights.org/en/mandatory-due-diligence>. Acesso em: 16 dec 2019.

HUMAN RIGHTS WATCH. Belgium: universal jurisdiction law repealed. [S.I.] 2003. Disponível em: <https://www.hrw.org/news/2003/08/01/belgium-universaljurisdiction-law-repealed>. Acesso em: 19 nov. 2019.

INTERNATIONAL CHAMBER OF COMMERCE. ICC Briefing: The UN Treaty Process on Business and Human Rights. International Chamber of Commerce. [S.1.], p. 3. 2019. Disponível em: < https://iccwbo.org/content/uploads/sites/3/2019/10/iccissues-brief-on-un-treaty-process-finalb.pdf > . Acesso em: 14 nov. 2019.

INTERNATIONAL MONETARY FUND. World Economic Database Outlook 2019. International Monetary Fund. Washington. 2019.

KPMG INTERNATIONAL. KPMG International survey of corporate sustainability reporting 2017. KPMG International Cooperative. [S.1.], p. 56. 2017. Disponível em:< https://assets.kpmg/content/dam/kpmg/xx/pdf/2017/10/kpmg_ survey-of-corporate-responsibility-reporting-2017.pdf >. Acesso em: 31 out. 2019.

MINISTRY OF CORPORATE AFFAIRS. Corporate Act 2013. New Delhi, 2013. Disponível em: < http://www.mca.gov.in/MinistryV2/companiesact2013.html>. Acesso em: 30 out. 2019.

MOVIMENTO DOS ATINGIDOS POR BARRAGENS. Hidrelétrica ameaça inundar cidade milenar e atinge milhares de pessoas no Curdistão. 07 jun. 2019. Disponível em: < https://www.mabnacional.org.br/noticia/hidrel-trica-amea-inundarcidade-milenar-e-atinge-milhares-pessoas-no-curdist >. Acesso em: 30 ago.2019. 
ORGANIZAÇÃO DA UNIDADE AFRICANA. Carta Africana dos Direitos Humanos e dos Povos. Banjul, 1981. Disponível em: < http://www.dhnet.org.br/direitos/sip/africa/banjul.htm >. Acesso em: 9 jan.2020.

Convenção de Bamako relativa à Interdição da Importação de Lixos Perigosos para a África e ao Controle da Movimentação Transfronteiras e à Gestão desses Lixos em África. Organização da Unidade Africana. Bamako, 1991.

Disponível

em:< https://treaties.un.org/doc/Publication/UNTS/Volume\%202101/v2101.pdf>. Acesso em: 3 dez. 2019.

ORGANIZAÇÃO DAS NAÇÕES UNIDAS. Carta da Terra. Paris, 1982. Disponível em:

https://www.mma.gov.br/estruturas/agenda21/_arquivos/carta_terra.pdf >. Acesso em: 23 mar. 2018

.Conferência das Nações Unidas sobre o Meio Ambiente e Desenvolvimento (Rio 92). ORGANIZAÇÃO DAS NAÇÕES UNIDAS. Nova Iorque. 1992.

. Convenção sobre os Direitos da Criança. UNICEF (Fundo das Nações Unidas para a Infância). 1989.

.Convenção sobre o Procedimento de Consentimento Prévio Informado Aplicado a certos Agrotóxicos e Sustâncias Químicas Perigosas Objeto de Comércio Internacional - Convenção de Roterdã. Organização das Nações Unidas. Roterdã. 1998.

.Declaração de Estocolmo sobre o Meio Ambiente Humano. [S.1.]. 1972. D Disponível em: <http://www.direitoshumanos.usp.br/index.php/Meio-

Ambiente/declaracao-de-estocolmo-sobre-o-ambiente-humano.html>. Acesso em 23 mar. 2018.

.Declaração do Rio sobre Meio Ambiente e Desenvolvimento. ORGANIZAÇÃO DAS NAÇÕES UNIDAS. [S.1.]. 1992. Disponível em:< http://www.onu.org.br/rio20/img/2012/01/rio92.pdf>. Acesso em: 23 mar.2018.

.Objetivos de Desenvolvimento do Milênio. Nova Iorque. 2000.

Pacto Internacional dos Direitos Civis e Políticos. Nova Iorque, 1966.

.Transformando nosso mundo: A Agenda 2030 para o desenvolvimento sustentável. ORGANIZAÇÃO DAS NAÇÕ̃ES UNIDAS. Nova Iorque. 2015. Disponível em: < https://www.undp.org/content/dam/brazil/docs/agenda2030/undpbr-Agenda2030-completo-pt-br-2016.pdf> . Acesso em: 19 out. 2019.

.ORGANIZAÇÃO INTERNACIONAL DO TRABALHO. Convenção da Organização do Trabalho n. 169 sobre Povos Indígenas e Tribais e Países Independentes. [S.I.]. 1989. 
.PROGRAMA DAS NAÇÕES UNIDAS PARA O MEIO AMBIENTE. Convenção de Roterdã sobre o Procedimento sobre o Consentimento Prévio Informado Aplicado a Certos Agrotóxicos e Substâncias Químicas Perigosas Objeto de Comércio Internacional. Roterdã, 1998. Disponível em:< https://www.mma.gov.br/estruturas/smcq_seguranca/_arquivos/roterd_texto_143.pdf >. Acesso em 03 nov.2019.

ORGANIZATION FOR ECONOMIC COOPERATION AND DEVELOPMENT. Annual Report on the OECD Guidelines for Multinational Enterprises 2017. Paris, p. 105, 2018. Disponível em: < http://mneguidelines.oecd.org/annualreportsontheguidelines.htm >. Acesso em: 03 nov. 2019.

OECD Due Diligence Guidance for Responsible Business Conduct Paris, 2018. Disponível em: <http://mneguidelines.oecd.org/due-diligence-guidance-forresponsible-business-conduct.htm>. Acesso em: 9 jan. 2020.

OECD Guidelines for Multinational Enterprises. Organization for Economic Co-operation Development. Paris, p. 59. 2011. Disponível em: < http://mneguidelines.oecd.org/guidelines/>. Acesso em: 9 jan. 2020.

PACTO GLOBAL Rede Brasil, 10 Princípios do Pacto Global. [S.I]. 2000. Disponível em: < https://www.pactoglobal.org.br/10-principios>. Acesso em: 2 Nov. 2019.

PARLAMENTO EUROPEU E DO CONSELHO DA UNIÃO EUROPEIA. Carta dos Direitos Fundamentais da União Europeia, Doc. 2000/C 364/01, de 7 de dezembro de 2000.

Relatório sobre as normas da União Europeia para as empresas que operam nos países em desenvolvimento: para um Código de Conduta Europeu. Parlamento Europeu. [S.1.]. 1998. Disponível em: < http://www.europarl.europa.eu/sides/getDoc.do?type=REPORT\&reference=A41998-0508\&language=EN >. Acesso em: 5 dez. 2019.

PARLAMENTO EUROPEU E DO CONSELHO DA UNIÃO EUROPEIA. Diretiva Seveso III, relativa à prevenção de acidentes graves envolvendo sustâncias químicas. Parlamento Europeu e do Conselho e da União Europeia. Bruxelas. 2012. Disponível em: <https://eurlex.europa.eu/LexUriServ/LexUriServ.do?uri=OJ:L:2012:197:0001:0037 :PT:PDF>. Acesso em: 3 nov. 2019.

PESTICIDE ACTION NETWORK UK. DowDupont: A contamination legacy, February 6th, 2018. Disponível em: < http://www.pan-uk.org/dowdupontcontamination-legacy/ >. Acesso em: 28 jun. 2018.

STAFF, C. Global 100 progress report. 31 Out 2019. Disponível em: $<$ https://www.corporateknights.com/magazines/2018-global-100-issue/progressreport-15166618/>. Acesso em: 31 out. 2019. 
THE FOREIGN CORRUPT PRACTICES ACT. U.S. Department of Justice. Washington DC. 1977. https://www.justice.gov/sites/default/files/criminalfraud/legacy/2012/11/14/fcpa-english.pdf > . Acesso em: 2 dez. 2019.

THE GUARDIAN. BHP facing 5 bn lawsuit from Brazilian victims of dam disaster, $2018 . \quad$ Disponível em: https://www.theguardian.com/environment/2018/nov/06/bhp-billiton-facing-5bnlawsuit-from-brazilian-victims-of-dam-disaster >. Acesso em: 4 dez. 2019.

THE GUARDIAN. Samarco dam collapse: one year on from Brazil's worst environmental disaster, 15 oct. 2016. Disponível em: < https://www.theguardian.com/sustainable-business/2016/oct/15/samarco-damcollapse-brazil-worst-environmental-disaster-bhp-billiton-vale-mining >. Acesso em: 16 jul. 2018.

THE PARLIAMENT OF THE COMMONWEALTH OF AUSTRALIA. Corporate Code of Conduct Bill 2000 [2002]. Commonwealth of Australia Parliament. [S.1.]. 2000.

Disponível em:< https://www.legislation.gov.au/Details/C2004B01333 >. Acesso em: 4 dez. 2019.

.(PARLIAMENTARY JOINT STATUTORY COMMITTEE ON CORPORATES AND SECURITIES). Report on the Corporate Code of Conduct Bill 2000. Commonwealth of Australia (Parliamentary Joint Statutory Committee on Corporates and securities). [S.1.]. 2001.

Disponível em: < https://www.aph.gov.au > senate > report > report_pdf>.

Acesso em: 4 dez. 2019.

UK GOVERNMENT. DEPARTMENT OF TRADE AND INDUSTRY. Corporate Social Responsibility: a Government update. Department of Trade and Industry UK. London, p. 26. 2004. Disponível em:< https://webarchive.nationalarchives.gov.uk/20081112200937/http://www.berr.gov.uk /files/file48771.pdf >. Acesso em: 3 dez.2019.

UK GOVERNMENT. Eliminating World Poverty: Making Globalisation Work for the Poor. UK Government. London, p. 108. 2000.

UK PARLIAMENT. UK Unfair Terms on Consumer Contracts Regulations [S.I.] 1991. Disponível em: <http://www.legislation.gov.uk/uksi/1999/2083/contents/made>. Acesso em: 20 nov 2019.

UNITED NATIONS ORGANIZATION. Brundtland Report. World Commission on Environment and Development: Our Common Future. [S.1.]. 1987.

. Charter of the United Nations and Statute of the International Court of Justice. San Francisco, 1945. Disponível em: < https://www.un.org/en/charter-unitednations/index.html >. Acesso em: 9 jan. 2010. 
.Commission on Transnational Corporations: report on the 13th session, 7-16 April, 1987. New York, 1987. Disponível em: < https://digitallibrary.un.org/record/134830?ln=em >. Acesso em: 11 nov. 2019.

Commission on Transnational Corporations Report on the Thirteenth Session Supplement n.o 9. Social and Economic Council. New York, p. 58. 1987.

.Draft United Nations Code of Conduct on Transnational Corporations. New York. 1983. Disponível em: < https://investmentpolicy.unctad.org/internationalinvestment-agreements/treaty-files/2891/download >.Acesso em: 9 jan.2020.

Norms on the Responsibilities of Transnational Corporations and Other Business Enterprises with Regard to Human Rights, U.N. Doc. E/CN.4/Sub.2/2003/12/Rev.2 (2003). New York, 2003.

E/CN.4/Sub.2/2003/12. Disponível em: < https://digitallibrary.un.org/record/498842 >. Acesso em: 3 nov. 2019.

Resolution A/RES/71/156 adopted by the General Assembly on 13 December 2016, 71/156 Observer status for the International Chamber of Commerce in the General Assembly. New York. 2016.

.The UN and Transnational Corporations. United Nations Intellectual History Prospect .New York: Ralph Bunch Institute for International Studies, v. 17, 2009.

.The Limburg Principles on the Implementation of the International Covenant on Economic, Social and Cultural Rights [UN doc. E/CN.4/1987/17, Annex; and Human Rights Quarterly, Vol. 9, p. 122-135, 1987.

.HUMAN RIGHTS COUNCIL. Elaboration of an international legally binding instrument on transnational corporations and other business with respect to human rights $\mathrm{A} / \mathrm{HRC} / \mathrm{RES} / 26 / 9$ - New York, 2014. Disponível em: < https://www.ihrb.org/pdf/G1408252.pdf >. Acesso em: 9 jan. 2019.

.INTERNATIONAL CRIMINAL COURT. Rome Statute of the Criminal Court. Rome, 1998. Disponível em: < https://www.icc-cpi.int/resourcelibrary/documents/rs-eng.pdf >. Acesso em: 10 jan.2020.

.INTERNATIONAL LAW COMMISSION. Draft Articles on Prevention from Hazardous Activities, with commentaries, 2001. New York, 2001.

.UNITED NATIONS CONFERENCE ON TRADE AND DEVELOPMENT. The United Nations Set of Principles and Rules on Competition" - The set of Multilaterally Agreed Equitable Principles and Rules for the Control of Restrictive Business Practices. Geneva , p. 20, 2000.

p. $31,2019$.

.World Investiment Report 2019 Special Economic Zones. Geneve, 
UNITED NATIONS ORGANIZATION. Basel Convention on the Control of Transboundary Movements of Hazardous Wastes and their Disposal. United Nations Organization. Basel. 1989. Disponível em: < http://www.basel.int/TheConvention/Overview/TextoftheConvention/tabid/1275/Def ault.aspx >. Acesso em: 3 dez. 2019.

Plan of Implementation of the World Summit on Sustainable Development. United Nations Organization. Johannesburg. 2002.

The Johannesburg Declaration on Sustainable Development. United Nations. Joahnnesburg. 2002. Disponível em :< https://ec.europa.eu/environment/archives/wssd/documents/wssd_pol_declaration.pd f >. Acesso em: 2 nov. 2019.

. Draft Norms on the Responsibilities of Transnational Corporations and Other Business Enterprises with regard to Human Rights. United Nations Organization. [S.1.]. 2003.

Resolution adopted by the Human Rights Council Elaboration of an international legally binding instrument on transnational corporations and other business enterprises with respect to human rights. Human Rights Council. [S.l.]. 2014.

Draft Report on the fifth session of the open-ended intergovernmental working group on transnational corporations and other business enterprises with respect to human rights. Human Rights Council. [S.1.], p. 26, 2020.

. FUNDO DAS NACÕES UNIDAS PARA A INFÂNCIA. Convenção sobre os Direitos da Criança. Paris, 1989.

UNITED NATIONS ORGANIZATION.HUMAN RIGHTS COUNCIL. A revised draft legally binding instrument to regulate, in international human rigths law, the activities of transnational corporations and other business enterprises. Human Rights Council. [S.1.], p. 19. 2019. Disponível em: < https://www.ohchr.org/en/hrbodies/hrc/wgtranscorp/pages/igwgontnc.aspx >. Acesso em: 12 nov. 2019.

.HUMAN RIGHTS COUNCIL. Draft Report on the fifth session of the open-ended intergovernmental working group on transnational corporations and other business enterprises with respect to human rights. A/HRC/43/XX. [S.l.]. 2020. Disponível em: < https://www.ohchr.org/Documents/HRBodies/HRCouncil/WGTransCorp/Session5/I GWG_5th_DraftReport.pdf>. Acesso em: 12 nov. 2019.

.UN GLOBAL COMPACT. UN Global Compact Integrity Measures Policy

\& FAQ. New York. 2016. Disponível em: < https://www.unglobalcompact.org/docs/about_the_gc/Integrity_measures/Integrity_ Measures_Note_EN.pdf >. Acesso em: 9 jan. 2020. 
UNITED STATES CODE. The Alien Tort Statute. (28 U.S.C. §1350. ATS). [S.I.] 1789.

U.S. CONGRESS.Corporate Code of Conduct Act. H.R.5377. Washington. 2006.

Disponível em: $<\quad$ https://www.congress.gov/109/bills/hr5377/BILLS109hr5377ih.pdf >. Acesso em: 5 dez. 2019.

U.S. CONGRESS. Sarbanes-Oxley Act. Washington, 2002. Disponível em: < https://www.sarbanes-oxley-101.com/SOX-404.htm >. Acesso em: 1 nov. 2019.

.U.S Comprehensive Anti-Apartheid Act de 1986. U.S. Congress. Washington. 1986. Disponível em:< https://www.congress.gov/bill/99thcongress/house-bill/4868>. Acesso em: 19 nov. 2019

U.S. HOUSE OF REPRESENTATIVES. 1974 Trade Act. [S.1.]. 1974. Disponível em: < http://www.washingtontradereport.com/TA74GSP.htm\#2461 >. Acesso em: 3 dez. 2019.

WORKING GROUP ON THE “ANTHROPOCENE”. What is the Anthropocene? -current definition and status. [S.I.]. Disponível em:< http://quaternary.stratigraphy.org/working-groups/anthropocene/>. Acesso em: 9 jan. 2020. 